\title{
First-YeAR StUdent PERSPECTIVES ON DiVERSITY IN THE ENGINEERING DESIGN ClASSROOM
}

\author{
Chirag Variawa \\ Northeastern University \\ c.variawa@neu.edu
}

\begin{abstract}
This paper investigates first-year engineering student assumptions about diversity in the classroom. Based on two qualitative surveys, administered at the start and end of term, a team of professors at Northeastern University in Boston, Massachusetts ask questions that elicit responses about what students assume their first year engineering classroom is like. The data from this study is categorized into student/student and student/instructor interfaces, with a more general set of findings that are applicable holistically to engineering education. This study suggests that students are moving from a "what engineering looks like" perception to a more "what engineering qualities and characteristics help the world" perception. The results of this exploratory study can help instructors get a better understanding of their students, to help enhance diversity in the classroom.
\end{abstract}

Keywords: Diversity, Inclusivity, Perception, First-year, Engineering Education.

\section{INTRODUCTION}

An engineering classroom, especially at the first-year level, is a diverse environment. Though a typical engineering class in North America has a mix of domestic and international students, this is only one attribute that characterizes student differences in the classroom. Diversity is not restricted to just ethnicity or country of origin but rather refers to a broader definition that encompasses differences in prior experiences as well. Apart from ethnicity, diversity can be seen via prior academic preparation (to some degree), language and communication skills, financial backgrounds, educational experiences, and other attributes that can contribute to student differences.

With increased diversity in a classroom, both students and instructors are often subject to differences in perspectives leading to a richer learning experience for everyone. Though, while it may not be appropriate to link differences in perspectives to diversity without scholarly research, this lens can be used as a starting point for instructors like us to better understand the engineering classroom, and this exploratory study aims to investigate connections between perspectives and diversity in the context of a first-year engineering classroom at a large American university.

As instructors, our goal is to ensure that all of our students have equal access to the instructional material. Here, we can choose to concentrate our work on examining the student, the instruction, or the barriers between them. In an attempt to explore this subject area generally, the exploratory work discussed in this paper focuses on the interface between the student and their engineering class environment - specifically, the interfaces between student/student and student/instructor. As an industrial engineer, this helps focus the broader study of diversity in engineering education into a more manageable context of interface design between and among students and instructors. By doing this, the goal is to view and appreciate student differences in the classroom, and observe if and how it affects their first-year engineering learning experience, and if/what these can be characterized as. The motivation behind studying the area of diversity in engineering education is to help appreciate, understand, and mitigate learning barriers that affect accessibility in diverse learning environments - specifically, engineering classrooms.

As engineers, we can characterize the engineering learning environment as a designed system. As McCahan [1] suggests, engineering classrooms can be viewed as a system with stakeholders, inputs and outputs, learning outcomes, and a very human element that includes the interfaces between the different people within that system. Taking this further, we can optimize this system using engineering approaches to increase accessibility for all users. Universal Instructional Design is one systemic approach that aims to change the learning environment to help increase access for as many learners to the greatest degree possible. However, this system doesn't work well for those individuals who require more than just a systemic change, but rather need a more individualized approach to increase accessibility to learning material in the classroom. 
To help appreciate these approaches, this preliminary study aims to characterize perspectives that students bring with them into an engineering learning environment. The focus of this study is on first-year engineering students as they enter a first-year core engineering design course. A qualitative survey is provided at the beginning and end of that course, questions on which probe general information about student perspectives including: influencers that affected their decision about choosing engineering, what they think engineering instructors are like, what they think engineering students are like, etc. At the conclusion of the second survey - which occurs at the end of term - the author and his colleagues attempt to characterize the perspectives the students had when they started versus at the end of the course.

The specific research questions are:

1. What prior assumptions do students have of diversity in the engineering classroom as they start their first-year engineering program?

2. What assumptions do students have about the diversity of their instructors?

3. What assumptions do students have about their peers (students)?

4. Are there any connections between what students say and prior studies on student assumptions in engineering education, and if so, what are they?

5. What are some of the general themes that students identify with diversity in engineering education?

\section{METHODOLOGY}

Two surveys were administered to first-year undergraduate engineering students at a large private university (Northeastern University) in Boston, Massachusetts. After acquiring ethics board approval, the first survey was administered less than a week into the start of the fall term. The second survey was administered during the last week of class. Both surveys were created using Google Forms, and were optional and anonymous. These studies took less than 5 minutes to complete, and were administered to a first-year core engineering design class that is common to all students in engineering.

The demographics of the class were that more than half of the students were domestic, the majority Caucasian, with approximately just less than half of the class a variety of ethnic and cultural backgrounds. Approximately $1 / 3$ of the class were women. There were approximately 5 students who were former members of the armed forces.

Not all of the 600 students participated in these surveys: due to the optional nature of this survey, 374 students participated in the first survey while 204 students participated in the second (largely due to logistical issues at the end of term).

The first survey asked students to think back to before they started class, and articulate their impressions on what a first-year engineering class would be like. Ideally, this survey would have been administered prior to the start of class, but this is infeasible. So, it was administered as near to the start date of class as possible. All of the questions on the surveys were agreed upon by the instructional team, and were vetted by the ethics board.

Between the first and second surveys, the students were part of a common first-year engineering design course. In this course, students were expected to work individually, in several different teams (some team projects were in pairs, while others were in groups of approx.. 5-8 people), do in-class and out-of-class assignments, write exams, and so on. These classes also included debates, lectures on theoretical aspects of teamwork, service learning components, 3D printing competitions, and several complex features that encouraged social interaction as well as technical learning.

The second survey was administered at the end of term. This survey asked questions to probe the same and similar areas as the first survey. This survey asked students about their first year learning, how their perspectives on diversity were like, now, having gone through the first-year engineering experience at this university, and opportunities to enhance diversity. For the open-ended content analysis, a single researcher first looked at all of the responses to categorize the responses. Further content analysis was then performed to tally frequencies of these responses.

\section{RESULTS/CONCLUSIONS}

\section{Perspectives on Faculty}

The results of the first question "Go back to when you were unpacking on move in day. What did you envision your first-year engineering professor to be like?" are qualitative. 374 students responded to this question, with $69 \%$ of them being male while approximately $30 \%$ of them were female. Categories that arise the most from the responses are keyed with the words "Old or Older", "Educated or Smart", "White Male", "No Expectation", "Foreign", "Female", "Strict or Challenging", and finally the stereotypical "Boring" or "Weird" or "Nerdy". These students, who just graduated from high school, might be forming this perception based on a typical stereotype of a professor being someone with experience and that comes with age. In identifying with believing their Professors would be "Caucasian or White" the total response rate was $11 \%$, with not much difference in gender in this 
category: the students almost-always associated this with being "male". Neither gender had a high expectation that their faculty would be female. Interestingly, less than 5\% of all respondents indicated that they envisioned their professor to be "Strict or Challenging". One category was related to typical stereotypes of an engineering professor such as "Boring, Weird, or Nerdy". Here, the students listed this category at less than a $4 \%$ response rate.

The post-survey follow-up question "After completing this semester, what do you envision your future engineering professors to be like?" results are also qualitative. Here, a total of 204 students responded. Categories that arise from the responses are keyed with the words "Enthusiastic, Helpful or Passionate", "Educated or Smart", "Mention of Age" such as middle aged, old or young, "Strict, Challenging or Demanding", "Mention of Gender", "Mention of Race" and finally the typical engineering stereotypes such as weird, nerdy, and others categorized under "Engineering Stereotypes". The students have clearly refocused their perception that a university professor is someone who is "old" as now $\sim 30 \%$ of all responses mention that they now expect their professor to be helpful, caring, enthusiastic, and passionate or motivated to teach - instead of just "old". Possible reasons for this change is due to a diverse team of first-year instructors (diversity in age, background, and teaching experience). As with the pre-survey the category with the second highest overall response of $23 \%$ was "Educated or Smart". This is an increase of $10 \%$ in the number of responses from the pre-survey. Here students again mentioned an advanced degree, needs to be intelligent or is smart, with similar comments as seen in the pre-survey.

\section{Perspectives on other students}

Students envisioned their first year class student population as being male, either white or of Asian descent, highly-educated, smart, and quite "nerdy". Contrary to many Canadian definitions of "Asian", which may tend to separate "East Asian" from "South Asian", the term "Asian" here refers to anyone with a background from that continent. In this study, such words are used as a snapshot of what students use to describe their classroom environment. Of the terms mentioned, the word "Male" is used about $40 \%$ more frequently as the next highest-used term, "Asia*" or "white". This shows that the students overwhelmingly believe that their engineering student population will be predominantly male. Similarly, the students do not imagine their firstyear student population to be much culturally diverse, other than being white or Asian; though they mention the root word "diver", the permutations of that word are not used to describe other ethnic groups. In addition, students believe that their classmates are educated, smart, and are of high academic standing. Though, the frequency of occurrence of these keywords are roughly $25 \%$ lower than the words used to describe ethnic background.

For the follow-up survey, the categories that arose from the responses are keyed with the words "Mostly Male", "America", "Helpful", "white", "sharing", "driven", "respectable", and several others. A number of responses included mentioning that students foresee their classes having far more female students than they thought initially. Students predict their future engineering classes to continue to be mostly male, albeit with a greater female student population, even though their responses on culture are not significantly different. Responses also suggest that their peers are more helpful, respectable, passionate, and innovative than they had originally assumed. When starting first-year, students generally thought that their peers would be "smart" and "nerdy". However, the vocabulary used to describe attitude has since shifted to "driven", "helpful", etc. at the end of their first-year experience.

\section{Perceptions on Engineering}

The results to the question "Why did you pick engineering as your major?" were categorized in a similar manner to the questions above. Categories that arise from the responses are keyed with the words "Science or Math", "Problem Solving", "Change the World", "Was Encouraged", "Creative or Hands on", "Stability or Money", "Fun or Interesting", and "Be Challenged". More than $40 \%$ of the students answering this question stated that they chose engineering because they were good at math and science. The majority of the respondents also cited a family member or close friend had experience with the engineering profession, and helped with the decision to study in this field. The responses that occurred with the least frequencies included a desire for a stable/wellpaying career, because it is fun/interesting, and because they desire a challenge. Notable in this last group of responses is that more women than men cited that they were looking for a challenge within engineering

The follow up survey had responses that were largely similar to the first study, with some marked differences. The largest difference was that the math and/or science theme was severely minimized (35\% reduction) and the fun/interesting $(27 \%$ increase $)$ and challenging $(15 \%$ increase) themes moved to the forefront of the student's opinions for persisting in engineering. The middle categories of solving problems, changing the world, and using their hands remained within a few percentage points of their pre-test values. One item to note is that the "change the world" response became a more common female answer. 


\section{Outcomes of the study}

Student's perspectives have changed over the span of these surveys. An overwhelming majority of responses show that students are shifting their perspectives on engineering from looks to qualities. Students now focus less on what engineers look like, and instead, focus more on the characteristics of instructors, peers, and the engineering profession - this is clear from the pre/post data. Students now appreciate that this profession is not about "us and them" but is instead more inclusive: you don't have to look a certain way to be an engineer.

As instructors try to create more inclusive learning environments, it is imperative that we begin to appreciate the value that diversity brings to the first-year engineering learning environment - and very importantly, the impact that has on changing student perspectives. The students in this study see that first-year engineering instructors are excited about engineering challenges and can detect the emphasis on problem solving. Even though the learning population at this university is diverse, it may not be as diverse as many Canadian institutions. However, students still value and perceive the benefits of greater diversity in the classroom. Specifically, students are beginning to see that diversity is not only limited to their student population, but to the instructional team of Professors as well. Therefore, perceived diversity is not only limited to the student body, but extends to the instructor population as well, and students perceive that as a part of their learning experience.

As instructors, we acknowledge the limitations of the findings from this study, and the confounding effects of out-of-class experiences between pre/post surveys - but emphasize that this is an exploratory first-step towards a more rigorous and systematic research goal of recording student assumptions. However, the importance of this study is highlighted when we begin to see that students feel more inclusive in environments where diversity is high, and where instructors are invested in promoting crosscultural and team-based learning. This can be seen in the shift of responses from wanting to be an engineer because they are good at math/science to finding it fun/interesting and challenging.

\section{Acknowledgements}

The author would like to thank his colleagues, the Northeastern University research team for their substantial contribution to this study: Prof. Susan Freeman, Prof. Don Goldthwaite, Prof. Beverly Jaeger, Prof. Courtney Pfluger, Prof. Kathryn Schulte-Graeme, and Prof. Richard Whalen.

\section{Reference}

[1] Variawa, C. and S. McCahan. "Design of the Learning Environment for Inclusivity.” Proc. of 117th ASEE Annual Conference and Exposition. ASEE Paper No. AC 20101195. Louisville, 2010. 